\title{
Perceived Organizational Support and Employee Engagement: Based on the Research of Organizational Identification and Organizational Justice
}

\author{
Kailiang Dai1 ${ }^{*}$, Xinyu Qin² \\ ${ }^{1}$ School of Business Administration, South China University of Science and Technology, Guangzhou, China \\ ${ }^{2}$ College of Continuing Education College, Guangdong University of Foreign Studies, Guangzhou, China \\ Email: ${ }^{* 377568032 @ q q . c o m ~}$
}

How to cite this paper: Dai, K.L. and Qin, X.Y. (2016) Perceived Organizational Support and Employee Engagement: Based on the Research of Organizational Identification and Organizational Justice. Open Journal of Social Sciences, 4, 46-57.

http://dx.doi.org/10.4236/jss.2016.412005

Received: November 21, 2016

Accepted: December 19, 2016

Published: December 22, 2016

Copyright $\odot 2016$ by authors and Scientific Research Publishing Inc. This work is licensed under the Creative Commons Attribution International License (CC BY 4.0).

http://creativecommons.org/licenses/by/4.0/ (c) (i) Open Access

\begin{abstract}
On the basis of theoretical research, this paper constructs the relationship model of perceived organizational support, organizational identification, employee engagement and organizational justice. With questionnaires from 350 employees in 28 provinces, we empirically tested that the organizational identification plays a mediating role and organizational justice has a moderating effect by using the correlation analysis and structural equation model and regression analysis. The results show that: firstly, perceived organizational support and employee engagement have significantly positive correlation, perceived organizational support applies directly positive influence on employee engagement; secondly, perceived organizational support can also play a role in employee engagement through organizational identification, in other words, organizational identification has partial mediating effect between perceived organizational support and employee engagement; thirdly, this paper verified that organizational justice plays a moderating role on the relationship between perceived organizational support and organizational identification.
\end{abstract}

\section{Keywords}

Perceived Organizational Support, Organizational Identification, Employee Engagement, Organizational Justice

\section{Introduction}

The formal CEO of GM once said, any company who wants to win in the fierce competition must try to make their own employees dedicated. It can be known that employee 
engagement has a significant positive impact on the organization's benefit and longterm development. The latest research report released by the well-known Gallup consulting firm showed that there are only $13 \%$ of the total staff in the world can be regarded as dedicated, and the proportion of employees in the work of the problem is as high as $63 \%$. Compared to the world average level, the proportion of dedicated employees in China is only $6 \%$ which makes Chinese enterprises feel anxious. It can be seen that China's enterprises who want to obtain a sustainable competitive advantage in the increasingly competitive market environment are required to improve their employee engagement urgently. So, what can domestic enterprises do to improve employee engagement? Chen Anqi [1] found that employees' organizational identification and employee engagement are positively correlated through the questionnaire survey of new employees in financial industry from four different cities. In addition, Sun Jianmin and Wang Zhen [2] analyzed 122 employees of 601 companies in domestic and found that organizational support can predict the role of organizational identification effectively. By empirical research, Gao Jianli [3] put forward that enterprises who pay attention to the correspondence between employees psychological capital and organizational can have a significant effect to improve employee engagement. In addition, Usmani and Jamal think that organizational justice has a significant effect on the employees' job behaviors and their work attitudes that ultimately result in a positive if confirmed or, otherwise negative organizational outcome [4]. Hence, such notion has great and significant implication for the individuals and the organizations as a whole [5]. It can be seen that the relationship among employee's organizational support, organizational identification, employee engagement and organization justice has been paid more and more attention by experts and scholars, meanwhile many valuable results have been achieved. However, the research on the internal mechanism of how organizational support affects employee engagement is to be deepened. Specifically, what is the internal mechanism of perceived organizational support and employee engagement? In order to answer these above questions, this paper will mainly focus on discussing the following three aspects: the influence of organizational support on employee engagement, 2) the mediating effect of organizational identification on organizational support and engagement, 3 ) to explore the regulatory role of organizational justice in the model of this study. And then we use psychological contract theory, social exchange theory and social equity theory and so on to explain those questions above.

\section{Literature Review and Research Hypothesis}

\subsection{The Relationship between Organizational Support and Organizational Identification}

Perceived Organizational Support (POS) was first put forward by Professor Eisenberger, he defined this concept as the degree to which employees believe that their organization values their contributions and cares about their well-being and fulfills socioemotional needs.

According to social identity theory (SIT), an organization may provide a basis for 
employees' self-construals, notably if it is perceived as prestigious or distinctive [6]. Organizational identification is thus a specific form of social identification and may be defined as employees' cognitive self-awareness of organizational membership [7]. Research has shown employees may identify to several targets including their work group, their department or their organization as a whole [8]. Identification will, in turn, impact employees' commitment [9].

According to the hierarchy of needs theory put forward by Masilou's, everyone needs to be taken care of. Emotional need is more detailed than the physical need. Bishop and Goldsby's research shows that if the emotional support, financial support or the career development support were perceived by the employee, their sense of belonging would be satisfied and thus their emotional attachment to the organization be strengthened. Organization support prompts employees to perceive their own value and the affirmation of the informal status, thereby enhancing the perception of organizational attractiveness. Because this process gives individuals a more positive social identity, as a result individuals are more likely to produce a sense of identity to those organizations that are able to give them a positive trait [10]. This is consistent with what David and Malayka concluded through the empirical study of the company's employees that employees perceived support from the organization has significantly positive impact on organizational identification [11]. Based on the above analysis, the following assumptions are put forward:

H1: Perceived organizational support is positively correlated with organizational identification.

\subsection{The Relationship between Perceived Organizational Support and Employee Engagement}

Employee engagement is a property of the relationship between an organization and its employees. An "engaged employee" is defined as one who is fully absorbed by and enthusiastic about their work and so takes positive action to further the organization's reputation and interests. Perceived organizational support reflects the organization's overall expectations of its members and recognition of personal value and their contribution to it in a subjective perception way. "Social exchange theory" and "reciprocity principle" have always been the theoretical basis of research on organizational support and employee engagement. The premise of the social exchange relationship is that if a person gives another person a favor, he believes that he will receive a corresponding return from the other person in the future [12]. Similarly, if organizational support was perceived by the employees, then they will believe that the organization will fulfill its obligations of exchange in the future and think that they are obligated to repay the organization, so they will work hard in order to obtain the material and spiritual rewards, thus realize social exchange. According to the principle of reciprocity, only when employees perceive support and caring from the organization that they will give positive organizational commitment and contribution and make active attitude or behavior changes in order to make effort to achieve organization goals. Related research shows that organizational support has a direct positive predictive effect on knowledge work- 
ers' job involvement [13]. The research on the negative behavior of the job involvement conducted by Wayne found that perceived organizational support can significantly inhibit the negative behavior of employees [14]. Based on the above analysis, the following assumptions are put forward:

$\mathrm{H} 2$ : Perceived organizational support is positively correlated with employee engagement.

\subsection{The Relationship between Organizational Identification and Employee Engagement}

Organizational identification is particularly important for the development of the organization, for it has a certain degree of causality with the employee engagement. Employees with high organizational identification will be actively involved into the work with actively attitude and behavior, for instance, the consistency of personal goals and organizational goals, to take initiative to remove the personal behavior that does not conform to the values of the organization, etc. Specifically, employees with high organizational identification will be more concerned with the organization's norms and values when they making decisions and be able to work diligently in accordance with the objectives and requirements of the organization without the supervision of others. Related organizational behavior research confirmed that organizational identification is significantly positive correlation with those indicators that help to achieve organizational goals such as employee satisfaction, organizational citizenship behavior, employee performance and so forth. Ashforth and Mael believe that the level of organizational identification plays a decisive role in the employees' work motivation and behavior [15]. The employees with high organizational identification tend to show a high level of support and a higher level of commitment to the organization, and their decision making is more consistent with the goals of the organization. Based on the above analysis, the following assumptions are put forward:

H3: Organizational identification is positively correlated with employee engagement.

\subsection{The Mediating Role of Organizational Identification}

On the basis of social identity theory, organizational identity is the psychological link connecting members and organizations, it is a process of members defined themselves and in the psychological belonging to the organization, in addition, organizational support is an important source of the organization identification [16]. Self presentation theory believes that the high level of organizational support can make the organization members feel content with what the organization provide to them, and then lead to the increase of the sense of identity of the organization. So they will work harder to prove their worth to the organization and worth the organization to provide more support, the results show a higher degree of employee engagement [17]. In addition, the organizational support theory shows that if employees perceived that the organization concerned with their welfare and value their contribution, employees will consciously join the membership of the organization to self-identity, so are more willing to immerse 
themselves in the role of the organization, to spare no effort to do their work and increase their self-expression performance in the work. As a result, a higher level of engagement reflected in them [18]. Based on the above analysis, the following assumptions are put forward:

H4: Organizational identification plays an intermediary role in the process of organizational support and employee engagement.

\subsection{The Moderating Effect of Organizational Justice}

Fairness issue has always been the eternal theme of the organizational. Researchers hold that if employees believe they are treated fairly, they would have a positive attitude towards their work, work results and superiors. In addition, according to the group value model, employees will regard organizational justice as their social information position in the organization. If the perceived organizational justice degree is high, then the employees will hold that the organization pays attention to the contribution of each member and trust them fully, and thus enhance staff's trust to organization. The trust to the organization will strengthen the member's sense of belonging and the ties between the two sides, so that employees will have a higher degree of organizational identification [19]. To some extent, organizational support transfers employees the expectations from the organization and provide necessary conditions to complete this expectation, organizational justice is the institutional basis that can guarantee the employees to complete the expectations from the organization. It is the interaction between organizational support and organizational justice that influences the identification of employees. Based on the above analysis, the following assumptions are put forward:

H5: Organizational justice plays a moderating role on the relationship between perceived organizational support and organizational identification as shown in Figure 1.

\section{Research Design}

\subsection{Samples}

In this study, a systematic sampling and stratified sampling are used to ensure the samples are representative. 350 respondents in a total of 52 companies are from different provinces and regions in China. In this survey, 350 questionnaires were sent out, 301 were recovered, the number of the effective questionnaires was 261 , the effective rate

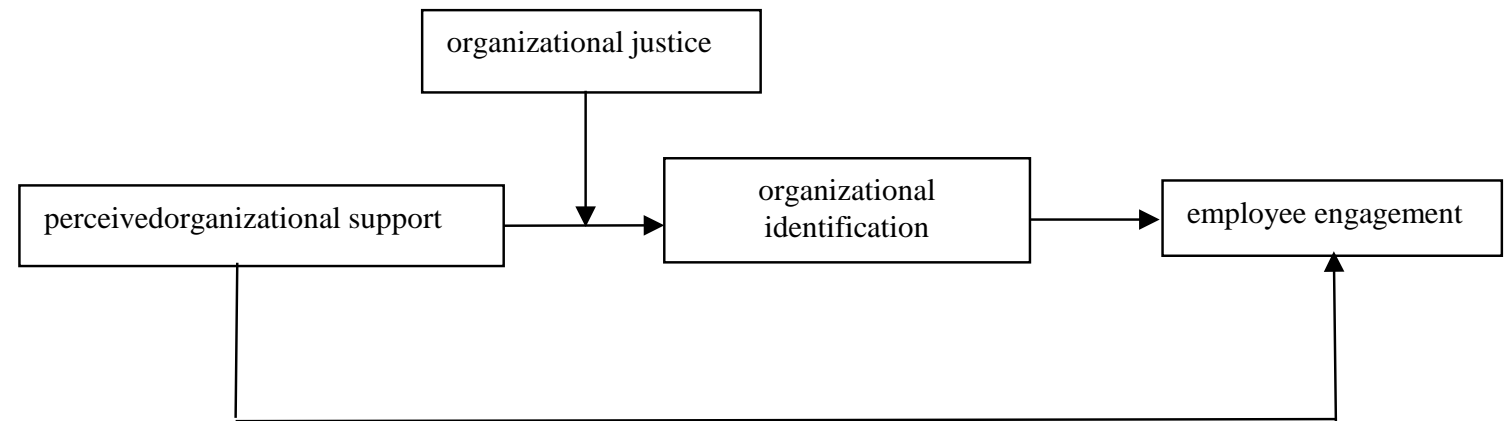

Figure 1. Research model. 
was $86.70 \%$. The basic characteristics of the sample are as follows: $20-25$ years old people accounted for $11.6 \%, 25$ - 39 years old accounted for $72.1 \%$, the remaining accounted for $16.3 \%$; technical staff accounted for more than $21.9 \%$, business management personnel accounted for $23.6 \%$, business staffs accounted for $18.9 \%$, accounting for $35.6 \%$ of the other; The percentage of the people work within 3 years in his company is accounted for $28.6 \%, 3$ - 5 years accounted for $25.9 \%$ and more than 5 years accounted for $45.5 \%$.

\subsection{Research Tools}

In this study, the scoring methods of the scale of the four variables are used Likert five point measure, all of the questions are asked from the positive aspect, from "very disagree" to "very agree" note 1 to 5 points respectively.

1) We use the questionnaire developed by Eisenberger which contains 8 questions to measure perceived organizational support. The sample items include "the company attaches great importance to my career goals and values". The factors of work support and life support are extracted by factor analysis. The internal consistency reliability is 0.918 .

2) We mainly referred organizational justice questionnaire developed by Niehoff and combined with the actual situation in China to revise it. It is measured from three dimensions of distributive justice, procedural justice and interactive justice which contains 15 items in all and the internal consistency reliability is 0.940 . The items in this questionnaire include "the remuneration I receive is fair in consideration of my work performance".

3) The measurement of organizational identification here we adopt Mael's [20] one dimension scale which consists of 6 items, for instance, the success of my company represents my own success. It is widely used in the current study of organizational identification, the average internal consistency coefficient is 0.85 .

4) We referred employee engagement scale developed by May which consists of a total of 8 items. For example, I am responsible for this work and have a high degree of professionalism and so on. The Cronbach alpha reliability coefficient was tested by the formal investigation of the effective sample test and the result was 0.850 , which showed that the scale has good reliability.

\subsection{Statistical Analysis}

In this study, AMOS 22.0 and SPSS 22.0 are used for statistical processing and analysis of the data. The methods of statistical analysis mainly include descriptive statistics, validity analysis, correlation analysis and regression analysis.

\section{Data Analysis and Research Results}

\subsection{Validity Analysis}

CFA analysis of the measurement model of organizational support, organizational identification, organizational justice and employee engagement was carried out on the 
AMOS 22.0. The results show that the model fits well, and the results are as follows.

Model fitting analysis results in Table 1 shows that $\chi^{2} / \mathrm{df}$ is less than 3, RMSEA value is less than 0.08 , RMR value is less than 0.05 , GFI, CFI values are greater than 0.9 , all are in the ideal range. It is showed that the fitting degree of the four variables in the model is acceptable. Therefore, the model of each variable in this study has high validity.

\subsection{Correlation Analysis}

We use SPASS 22.0 to do the correlation analysis, the mean value, standard deviation, correlation analysis and internal consistency reliability coefficient of each variable are shown in Table 2.

From Table 2 we can see that the mean value of the four variables in this study ranged from 3.79 to 3.95 , the standard deviation ranged from 0.529 to 0.676 , and the $\alpha$ coefficients of the variables are above 0.8 , indicating that the four variables all have good reliability. The correlation coefficient between perceived organizational support and organizational identity reached a significant level of $\mathrm{P}<0.01$, in addition, each of perceived organizational support, organizational justice and organizational identification reached a significant level of $\mathrm{P}<0.01$ with employee engagement respectively. Furthermore, the correlation coefficients are between 0.715 and 0.787 , all are significantly positive correlation.

\subsection{Regression Analysis}

From Table 3 we can see that in M1, perceived organizational support has a significant impact on organizational identification in the significant level of 0.001 of has on the variance of the variance explained 53.2\%, which account for $53.2 \%$ of the total variance altogether, so as to verify the hypothesis 2 . In M2, we explored the role of organizational

Table 1. Confirmatory factor analysis of each variable $(\mathrm{N}=301)$.

\begin{tabular}{cccccccc}
\hline Variable & $\chi^{2}$ & $\mathrm{df}$ & $\chi^{2} / \mathrm{df}$ & GFI & CFI & RMR & RMSEA \\
\hline Perceived Organizational Support & 9.625 & 14 & 0.687 & 0.991 & 1.000 & 0.011 & 0.000 \\
Organizational Justice & 167.138 & 74 & 2.259 & 0.925 & 0.964 & 0.026 & 0.065 \\
Organizational Identification & 20.016 & 8 & 2.502 & 0.978 & 0.981 & 0.016 & 0.071 \\
Employee Engagement & 49.052 & 18 & 2.725 & 0.960 & 0.970 & 0.024 & 0.076 \\
\hline
\end{tabular}

Table 2. Descriptive statistics, correlation analysis and internal consistency reliability coefficient of each variable $(\mathrm{N}=301)$.

\begin{tabular}{ccccccc}
\hline Variable & M & SD & 1 & 2 & 3 & 4 \\
\hline 1) Perceived Organizational Support & 3.85 & 0.605 & $\mathbf{0 . 8 7 9}$ & & & \\
2) Organizational Justice & 3.79 & 0.676 & $0.771^{\star *}$ & $\mathbf{0 . 9 4 3}$ & & \\
3) Organizational Identification & 3.95 & 0.529 & $0.731^{\star *}$ & $0.657^{\star *}$ & $\mathbf{0 . 8 3 7}$ & \\
4) Employee Engagement & 3.94 & 0.585 & $0.715^{\star *}$ & $0.787^{\star *}$ & $0.722^{\star *}$ & $\mathbf{0 . 8 7 8}$ \\
\hline
\end{tabular}

Note 1 : $^{* *}: \mathrm{P}<0.01{ }^{*}: \mathrm{P}<0.05$ (two-tailed test); Note 2 : The bold type part in the table is the reliability value of each variable dimension. 
support and organizational justice on organizational identification in which $\mathrm{F}$ value is 54.031 ( $\mathrm{p}<0.001$ ), and the regression equation was significant. In M3, the interaction between organizational support and organizational justice is introduced into the regression equation, the interaction between organizational support and organizational justice has a positive effect on organizational identification at the significant level of $0.05, \mathrm{~F}$ value was 48.788 and the regression equation was significant, that is, the positive relationship between organizational support and organizational identification was strengthened. So the organizational justice played a moderating role in the relationship between perceived organizational support and organizational identification. Figure 2 shows the relationship between organizational justice and perceived organizational support that the positive effect of organizational support on organizational identification is strengthened with the increase of employees' organizational justice. Therefore, Hypothesis 5 is tested.

In order to study the influence of organizational support and organizational identification on employee engagement, the regression model with employee engagement as the dependent variable was established, and the multiple regression analysis was conducted. In M4, M5 and M6 employee engagement is the dependent variables and organizational identification are the independent variable. In addition its regression results

Table 3. Results of multiple regression analysis $(\mathrm{N}=301)$.

\begin{tabular}{|c|c|c|c|c|c|c|c|}
\hline \multirow[b]{2}{*}{ Independent variable } & \multirow[t]{2}{*}{ Dependent variable } & \multicolumn{3}{|c|}{ Organizational Identification } & \multicolumn{3}{|c|}{ Employee Engagement } \\
\hline & & M1 & M2 & M3 & M4 & M5 & M6 \\
\hline perceived orgar & ional support & $0.735^{\star * *}$ & $0.547^{\star * *}$ & \multicolumn{3}{|c|}{$0.492^{\star * *} 0.712^{\star * *}$} & $0.395^{\star * *}$ \\
\hline organizat & 1 justice & & $0.240^{* * *}$ & \multicolumn{2}{|l|}{$0.223^{* * *}$} & \multirow[b]{2}{*}{$0.716^{* * *}$} & \\
\hline Organization & lentification & & & & & & $0.432^{\star * *}$ \\
\hline \multicolumn{3}{|c|}{ Organizational Identification ${ }^{\star}$ organizational justice } & & \multicolumn{2}{|l|}{$0.116^{*}$} & & \\
\hline & & 0.514 & 0.023 & 0.009 & 0.484 & 0.499 & 0.086 \\
\hline Adju & $\mathrm{R}^{2}$ & 0.532 & 0.553 & 0.560 & 0.505 & 0.521 & 0.591 \\
\hline & & \multicolumn{3}{|c|}{$57.729^{\star \star \star} 54.031^{\star \star \star} 48.788^{\star * *}$} & $52.0^{* * *} 5$ & $55.300^{* * *}$ & $\star 62.888^{\star * *}$ \\
\hline
\end{tabular}

Note: ${ }^{* * *}$ means $\mathrm{P}<0.001 ;{ }^{* *}$ means $\mathrm{P}<0.01{ }^{*}$ means $\mathrm{P}<0.05$ (two-tailed test).

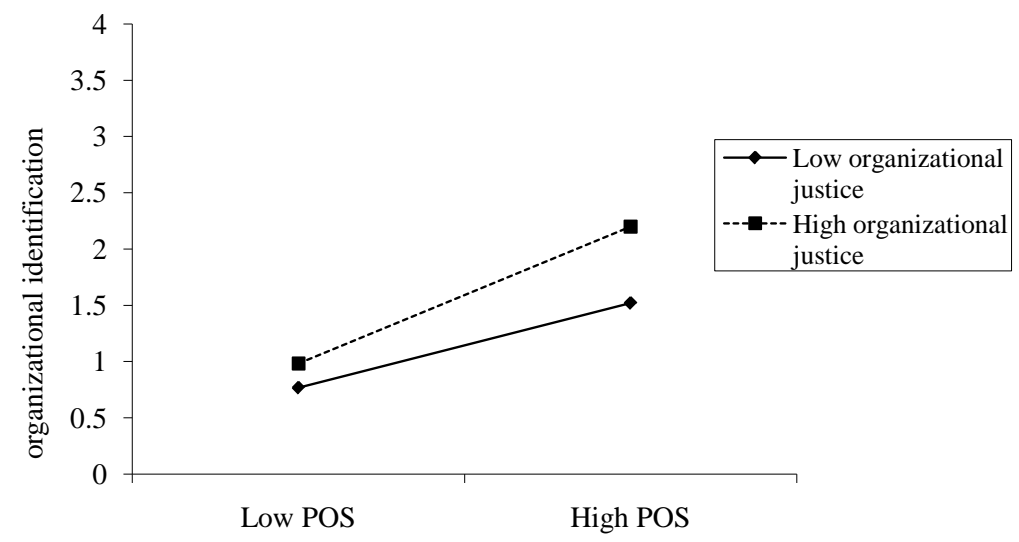

Figure 2. The moderating effect of organizational justice. 
as shown in Table 3.

In M4 we explored the effect of organizational support on employee engagement. The perceived organizational support has significant effect on employee engagement at the 0.001 level, $\mathrm{F}$ value was $52(\mathrm{P}<0.001)$, so the regression equation was significant. The effect of perceived organizational support on employee engagement was significant, and hypothesis 1 was tested. In M5, considering the role of organizational identification on employee engagement, organizational identity has a significant impact on employee engagement at a significant level of 0.001 , and the regression equation is remarkable. Hypothesis 3 was tested. In M6, besides considering the sense of organization support, we add the variable of organization identification in order to explore their influence on employee engagement. It is turned out that perceived organizational support has a significant positive effect on employee engagement $(r=0.395, \mathrm{P}<0.001)$, and organizational identification still has a significant positive effect on employee engagement $(\mathrm{r}=0.432, \mathrm{P}<0.001)$. It shows that organizational identification plays a partial intermediary role in the relationship between perceived organizational support and employee engagement. Figure 3 shows the partial intermediary model of organizational identification made by the structure equation.

\section{Conclusions and Discussions}

\subsection{Research Conclusions}

Conclusion 1: Organizational support significantly affects organizational identification. If the organization's support can be clearly perceived by employees, it will help to promote the employees' sense of identity to the organization.

Conclusion 2: Organizational identification significantly affects employee engagement. The higher the organizational identification of the employees, the stronger sense of belonging they have to the organization and they are more willing to show support to the organization, thus reflecting a higher level of engagement.

Conclusion 3: Organizational support significantly affects employee engagement. When employees perceive the support from the organization, the employee's belonging sense to the organization will be strengthened. It makes the employees work hard to

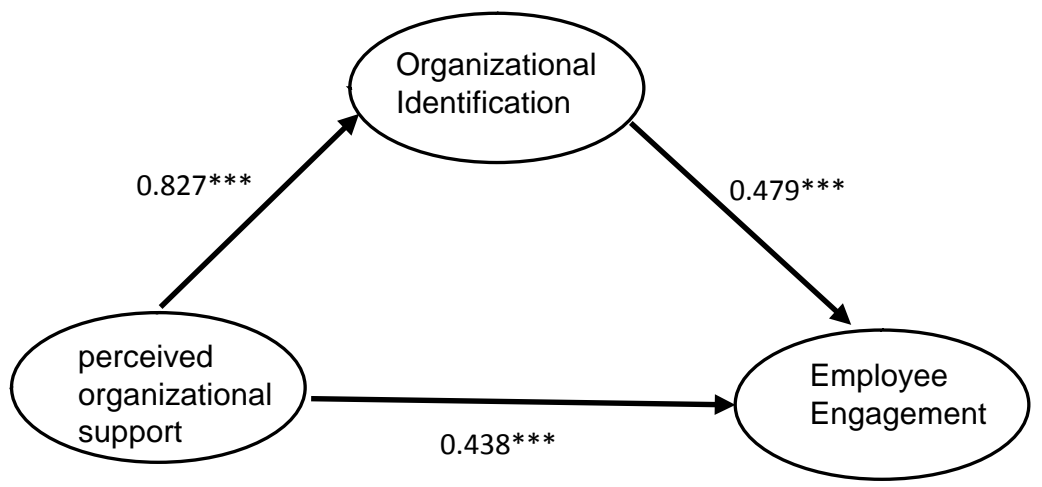

Figure 3. The partial intermediary model of organizational identification (note: ${ }^{* * *}$ means $\mathrm{P}<0.001$; ${ }^{* *}$ means $\mathrm{P}<0.01$; ${ }^{\star}$ means $\mathrm{P}<0.05$ (two-tailed test)). 
achieve the organization's goals, showing a higher degree of employee engagement.

Conclusion 4: Organizational identification plays a partial mediating role in the relationship between organizational support and employee engagement. According to the theory of self presentation, when the perceived organizational support is in high level, the employee will be satisfied with the guarantees provided by the organization and the value of themselves. As a result, it will enhance their organizational identity and further they show a higher level of engagement.

Conclusion 5: Organizational justice plays a moderating effect on the relationship between perceived organizational support and organizational identification. Based on social equity theory, organizational justice will have a certain impact on the formation of organizational identity. When employees perceive that they are treated fairly, the relationship between perceived organizational support and organizational identification will be more significant.

\subsection{Management Implications}

1) Though employee engagement is important, enterprises should not request it with nothing. Instead, they should first give employees a duty, give the necessary conditions required to complete the work to the staff, pay attention to their contributions and cares about their welfare in order to improve employee's perceived support from the organization. It is the prerequisite that ensure the employees to get job satisfaction and maintain high engagement, and not have the order reversed.

2) In the course of daily personnel management, enterprises should pay attention to the employees' identification to the enterprise, not only provide all the necessary support to the employees, but also promote the sense of belonging and the consciousness that they are bound up with the fate of the organization through advocating and propagating of the enterprise core culture. Thus can make the employees to maintain a high degree of consistency with the organization both in mind and behavior, and has more positive effect to improve employee engagement.

3) Enterprises should not just care about the actual supply of employees during the personnel management. On one hand, they need to establish a good institutional environment to ensure the organization is relatively fair. On the other, it is more important to know about their perception of the support from the organization from the individual angel. Minimize or avoid the negative effects on the organization produced by the employees' unfair psychological.

\subsection{Theoretical Contributions}

This research, not only enriched the study of employee antecedent variable of employee engagement, but also deepen the study of the mechanism of organizational support, organizational identification and employee engagement, complemented the previous research through the empirical test. In addition, we prove that organizational identification plays a partial mediating role in the relationship between organizational support and employee engagement by structural equation. Furthermore, this is the first study to 
explore the moderating effect of organizational in the relationship between perceived organizational support and organizational identification. The results of this study fill the blank of the research of organization justice in a certain extent and provide new ideas for future research development.

\section{References}

[1] Chen, A.Q. (2012) A Study on the Influence of Organizational Identification on Engagement of New Employees in Financial Industry. Shandong University, Jinan.

[2] Wan, Z. and Sun, J.M. (2011) Human Resource Management Practice, Perceived Organizational Support and Employee Commitment and Identification: A Cross-Level Study. Economic Management Journal, 29, 32-36.

[3] Gao, J.L. and Sun, M.G. (2015) Study on the Function Route of Psychological Capital, Perceived Organizational Support to Employee Engagement of Research and Development Personnel. Science and Technology Management Research, 35, 231-236.

[4] Usmani, S. and Jamal, S. (2013) Impact of Distributive Justice, Procedural Justice, Interactional Justice, Temporal Justice, Spatial Justice on Job Satisfaction of Banking Employees. Review of Integrative Business and Economics Research, 2, No. 1.

[5] Yesil, S. and Dereli, S.F. (2013) An Empirical Investigation of the Organizational Justice, Knowledge Sharing and Innovation Capability. Procedia, Social and Behavioral Sciences, 75, 199-208. https://doi.org/10.1016/j.sbspro.2013.04.023

[6] Ashforth, B.E. and Mael, F. (1989) Social Identity Theory and the Organization. Academy of Management Review, 14, 20-39.

[7] Bergami, M. and Bagozzi, R.P. (2000) Self-Categorization, Affective Commitment and Group Self-Esteem as Distinct Aspects of Social Identity in the Organization. British Journal of Social Psychology, 39, 555-577. https://doi.org/10.1348/014466600164633

[8] Johnson, M.D., Morgeson, F.P., Ilgen, D.R., Meyer, C.J. and Lloyd, J.W. (2006) Multiple Professional Identities: Examining Differences in Identification across Work-Related Targets. Journal of Applied Psychology, 91, 498-506. https://doi.org/10.1037/0021-9010.91.2.498

[9] Tyler, T.R. and Blader, S.L. (2000) Cooperation in Groups: Procedural Justice, Social Identity, and Behavioral Engagement. Psychology Press, Philadelphia, PA.

[10] Dutton, J.E. and Harquail, C.V. (1994) Organizational Images and Member Identification. Administrative Science Quarterly, 39, 239-263. https://doi.org/10.2307/2393235

[11] Sluss, D.M., Klimchak, M. and Holmes, J.J. (2008) Perceived Organizational Support as a Mediator between Relational Exchange and Organizational Identification. Journal of Vocational Behavior, 73, 457-464. https://doi.org/10.1016/j.jvb.2008.09.001

[12] Settoon, R.P., Bennett, N. and Liden, R.C. (1996) Social Exchange in Organizations: Perceived Organizational Support, Leader-Member Exchange, and Employee Reciprocity. Journal of Applied Psychology, 81, 219-227. https://doi.org/10.1037/0021-9010.81.3.219

[13] Liang, G.Q. and Zhang, W. (2015) Effect of Organizational Support on Job Involvement: the Mediating Role of Psychological Capital. Management and Administration, No. 9, 135137.

[14] Wayne, S.J., Shore, L.M., Bommer, W.H., et al. (2002) The Role of Fair Treatment and Rewards in Perceptions of Organizational Support and Leader-Member Exchange. Journal of Applied Psychology, 87, 590-598. https://doi.org/10.1037/0021-9010.87.3.590

[15] Ashforth, B.E. and Mael, F. (1989) Social Identity Theory and the Organization. Academy 
of Management Review, 14, 20-39.

[16] Tajfel, H. (1978) Differentiation between Social Groups: Studies in the Social Psychology of Intergroup Relations. Academic Press, Salt Lake City.

[17] Thibaut, J.W. and Walker, L. (1975) Procedural Justice: A Psychological Analysis. Duke Law Journal, 1977, No. 6.

[18] Eisenberger, R., Cummings, J., Armeli, S., et al. (1997) Perceived Organizational Support, Discretionary Treatment, and Job Satisfaction. Journal of Applied Psychology, 82, 812-820. https://doi.org/10.1037/0021-9010.82.5.812

[19] Tyler, T.R. (1989) The Psychology of Procedural Justice: A Test of the Group-Value Model. Journal of Personality \& Social Psychology, 57, 830-838. https://doi.org/10.1037/0022-3514.57.5.830

[20] Mael, F. and Ashforth, B.E. (1992) Alumni and Their Alma Mater: A Partial Test of the Reformulated Model of Organizational Identification. Journal of Organizational Behavior, 3, 103-123. https://doi.org/10.1002/job.4030130202

Submit or recommend next manuscript to SCIRP and we will provide best service for you:

Accepting pre-submission inquiries through Email, Facebook, LinkedIn, Twitter, etc.

A wide selection of journals (inclusive of 9 subjects, more than 200 journals)

Providing 24-hour high-quality service

User-friendly online submission system

Fair and swift peer-review system

Efficient typesetting and proofreading procedure

Display of the result of downloads and visits, as well as the number of cited articles

Maximum dissemination of your research work

Submit your manuscript at: http://papersubmission.scirp.org/

Or contact jss@scirp.org 